\title{
EDUCAÇÃO AMBIENTAL NO ÂMBITO ESCOLAR: ANÁLISE DO PROCESSO DE ELABORAÇÃO E APROVAÇÃO DA BASE NAÇIONAL COMUM CURRICULAR (BNCC)
}

Lucas de Oliveira ${ }^{1}$ Zysman Neiman ${ }^{2}$

Resumo: A despeito de ser uma abordagem prevista desde a constituição de 1988 e regulamentada por Diretrizes Nacionais bem como por diversos instrumentos da legislação, a Educação Ambiental só se consolidou no currículo formal de ensino a partir da aprovação dos PCNs em 1998. O "Tema Transversal Meio Ambiente", garantia uma abordagem interdisciplinar no âmbito escolar que cumpria a necessidade do debate. No entanto, o atual governo federal está propondo uma reformulação, de modo a implantar uma nova BNCC, na qual a Educação Ambiental não está contemplada. Este artigo visa descrever o processo de elaboração e aprovação da BNCC analisando sua implicação para o futuro da Educação Ambiental no ensino formal.

Palavras-chave: BNCC; Educação Ambiental; Educação Básica.

Abstract: Despite being an approach foreseen since the 1988 constitution and regulated by National Guidelines as well as by several instruments of the legislation, Environmental Education was only consolidated in the formal teaching curriculum after the approval of the PCNs in 1998. The "Middle Cross Theme Environment ", guaranteed an interdisciplinary approach in the school environment that fulfilled the need for debate. However, the current federal government is proposing a reformulation, in order to implement a new BNCC, in which Environmental Education is not included. This article aims to describe the process of preparing and approving the BNCC by analyzing its implications for the future of Environmental Education in formal education.

Keywords: BNCC; Environmental Education; Basic Education.

\footnotetext{
${ }^{1}$ Mestre em Ensino de Ciências e Matemática pela Universidade Federal de São Paulo.

E-mail: lucas oliver14@hotmail.com.

2 Professor da Universidade Federal de São Paulo. E-mail: zneiman@gmail.com
} 


\section{Introdução}

Segundo Dias (2004, p.80), no ano de 1972, o Brasil assinou a Declaração da ONU sobre o Meio Ambiente Humano e no ano seguinte o presidente criou a Secretaria Especial do Meio Ambiente (SEMA), dentro do Ministério do Interior.

$\mathrm{Na}$ década de 1980, o Brasil passava por momentos importantes na política, com "as diretas já" e concomitantemente com os debates sobre a nova Constituição Federal. Para a educação e meio ambiente foram momentos de evoluções e avanços. Vale ressaltar que foi nesta década que o Brasil conseguiu as Bases Legais para uma relação entre a educação e meio ambiente, ganhando novas leis ambientais (CZAPSKI, 1998).

Com a Constituição de 1988, a Educação Ambiental se tornou obrigatória em todos os níveis de ensino, mas não poderia ser como uma disciplina, mantendo-se os princípios e objetivos que foram adotados em Tbilisi. Essa década de 1990 foi marcada por desastres ambientais fora do Brasil, dentre os principais pode-se citar um vazamento de gás venenoso em Bhopal na Índia e o maior acidente nuclear no mundo, o de Chernobyl, afetando milhões de pessoas e deixando áreas inabitadas devido a radioatividade (OLIVEIRA, 2016; PINHEIRO, 2009)

A Educação Ambiental tem como objetivo, conscientizar todos os cidadãos que os problemas ambientais fazem parte de suas vidas e que só podem ser resolvidos com sua participação ativa, possibilitando 0 desenvolvimento de atitudes para o exercício da cidadania e promovendo a conscientização e o envolvimento das pessoas com atividades em defesa da sustentabilidade do nosso planeta. Segundo a Política Nacional de Educação Ambiental - PNEA (Lei 9.795/1999), a Educação Ambiental é definida como:

um processo por meio dos quais o indivíduo e a coletividade constroem valores sociais, conhecimentos e habilidades, atitudes e competências voltadas para conservação do meio ambiente, bem de uso comum do povo, essencial à sadia qualidade de vida e sua sustentabilidade (BRASIL, 1999).

A PNEA determina a inclusão da Educação Ambiental em todos os níveis de ensino, com a missão de contribuir com a educação para um desenvolvimento sustentável (BARBOSA, 2008). Neste contexto, essa abordagem foi inserida no ensino básico no Brasil a partir da aprovação dos Parâmetros Curriculares Nacionais (PCN), no final dos anos 1990. O "Tema Transversal Meio Ambiente", sugerido pelos PCN garantia uma abordagem interdisciplinar no âmbito escolar que cumpria a necessidade do debate extremamente importante para os tempos atuais, tenda a sustentabilidade como princípio fundamental. 
No entanto, o governo federal propôs entre 2017 e 2018 uma reformulação tanto no ensino fundamental quanto no médio, de modo a implantar uma nova Base Nacional Curricular Comum (BNCC), na qual os temas transversais (a Educação Ambiental, inclusive) não estão contemplados de maneira explícita.

Vale ressaltar que a reforma do ensino médio, aprovada em 2017, flexibilizou o currículo, definindo que os conhecimentos essenciais totalizariam 1800 horas e que no restante do tempo, o aluno escolherá o que deseja estudar nas seguintes áreas: I - linguagens e suas tecnologias; II - matemática e suas tecnologias; III - ciências da natureza e suas tecnologias; IV - ciências humanas e sociais aplicadas; V - formação técnica e profissional (BRASIL, 2017b)

A BNCC do ensino médio foi definida pelo MEC e aprovada no Conselho Nacional de Educação (CNE) em dezembro de 2018. Sua implantação demandará uma grande discussão por toda a sociedade e principalmente entre os educadores.

Dentre os "itinerários formativos" para os estudantes, previstos pela reforma do ensino médio, haveria possibilidade de inserir a Educação Ambiental, colocando-a de uma forma interdisciplinar, ou seja, dentro de atividades propostas em cada disciplina? Afinal, parte da formação $(40 \%)$ será voltada para a ênfase escolhida pelo aluno, e o restante do tempo, para a formação comum, definida pela Base Nacional Comum Curricular.

O presente trabalho tem como objetivo geral, por meio de uma revisão bibliográfica e documental, analisar como a Educação Ambiental está incluída no ensino formal por meio das políticas públicas vigentes e a proposta de alteração a ser implementada pela Base Nacional Comum Curricular (BNCC). De modo mais específico, analisou-se todo o seu processo de elaboração e aprovação que teve seu documento final publicado em dezembro de 2018, de modo a verificar como a Educação Ambiental está contemplada, seus avanços ou retrocessos e as mudanças que ela sofreu em relação aos documentos anteriormente existentes, sendo o mais importante os $\mathrm{PCN}$, principalmente dentro do conteúdo do Ensino Fundamental e Médio.

\section{Métodos}

Inicialmente foi realizada uma análise documental por meio da consulta às políticas públicas de Educação Ambiental vigentes até 2017, e às versões debatidas da Base Nacional Comum Curricular, além de leitura de alguns artigos científicos sobre o tema.

Também foram acompanhados presencialmente e a distância alguns fóruns de debate da BNCC, dentre eles audiências públicas realizadas em todo - Brasil, disponibilizadas na internet pelo governo Federal, com ênfase para as cinco últimas audiências realizadas entre julho e setembro de 2017 (Ensino Fundamental), sendo uma em cada região do país, de modo a se obter um diagnóstico de como o processo transcorreu. 
Buscou-se analisar, mais especificamente, como Educação Ambiental está presente nos dois principais documentos curriculares: PCN e Base Nacional Comum Curricular, para assim verificar se houve avanços ou retrocessos na inserção da Educação Ambiental no ensino formal entre ambos.

Para isso, foi realizada uma pesquisa qualitativa que, segundo Lüdke e André (1986), busca "o porquê" das coisas, sem considerar aspectos quantitativos dos dados obtidos. Como dito anteriormente, este estudo está baseado em análises documentais e participações de reuniões e encontros que discutiram a Base Nacional Comum Curricular, de modo a permitir uma melhor análise do fenômeno pesquisado, aprofundando nas discussões desses documentos oficiais do governo brasileiro.

\section{Discussão sobre os documentos curriculares}

Segundo Novicki e Souza (2010), a temática ambiental está inserida no Brasil nos espaços formal e não formal de ensino e se faz notar tanto a Constituição Federal de 1988, quanto em outras esferas das políticas vinculadas à temática ambiental, como a Política Nacional de Meio Ambiente (PNMA) e a Política Nacional de Educação Ambiental (PNEA). No entanto, estritamente ao ensino formal, existem hoje no Brasil três que abordam (ou deveriam abordar) a questão ambiental no currículo escolar: as Diretrizes Curriculares Nacionais (DCN), os Parâmetros Curriculares Nacionais (PCN) e a Base Nacional Comum Curricular (BNCC).

\section{Diretrizes Curriculares Nacionais para a Educação Ambiental}

As Diretrizes Curriculares Nacionais para a Educação Ambiental (DCNEA) foram aprovadas e homologadas em junho de 2012 e constituem um documento de mais de 500 páginas que atende uma exigência constitucional (artigos 22 e 210) que afirmam que "compete privativamente à União legislar sobre [...] diretrizes e bases da educação nacional" e prevê que "serão fixados conteúdos mínimos para o ensino fundamental, de maneira a assegurar formação básica comum e respeito aos valores culturais e artísticos, nacionais e regionais" (BRASIL, 2013).

Com base nesses dois artigos, as DCNEA estabeleceram uma base para que se possa orientar, articular e desenvolver a educação básica do país respaldado por lei, garantindo uma regulação do ensino. É um documento amplo e direcional para todos.

Suas Diretrizes foram sendo revisadas com o passar do tempo, de modo que fossem constantemente atualizadas. Um exemplo destas revisões é a implementação de informações do Ensino Fundamental de nove anos, algo que foi incrementado como um parecer em novembro de 2010 (BRASIL, 2013).

Para a fundamentação e finalização desta Diretriz, foi necessária a participação dos sistemas de ensino, sociedades, eventos que discutiram a 
Educação Ambiental, dentre eles o VII Fórum Brasileiro de Educação Ambiental realizado em Salvador (BA).

Este documento se baseia em leis, fazendo com que tenha marco legal garantindo o seu amparo, sendo leis e artigos da Constituição Federal de 1988, dentre elas o artigo 225, que é dedicado exclusivamente ao Meio Ambiente e também a Lei 9.795/1999 que fala especificamente sobre a Educação Ambiental e institui a Política Nacional de Educação Ambiental (PNEA).

De acordo com as DNCEA a Educação Ambiental deve estar presente nos currículos de todas as disciplinas, não sendo necessária a criação de uma disciplina para a Educação Ambiental, pois a mesma deve ter caráter transversal, devendo ser integrada, contínua e permanente com todas as outras disciplinas e atividades escolares de todos os níveis educacionais. É enfatizada a interdisciplinaridade e a construção de uma "cidadania ambiental". Trata-se de um documento amplo que foi criado para auxiliar e Instituições de Ensino a abordarem adequadamente a Educação Ambiental.

\section{Parâmetros Curriculares Nacionais (PCN)}

Os Parâmetros Curriculares Nacionais (PCN) foram aprovados em 1988 e constituem um documento dividido em diversos arquivos, sendo que cada arquivo aborda por uma disciplina específica ou um ciclo de ensino, como exemplo Fundamental I ou Fundamental II. Há um volume especial que apresenta os chamados Temas Transversais, dentre eles o Meio Ambiente.

A primeira parte do arquivo dos PCN que aborda o Temas Transversal Meio Ambiente lembra muito as Diretrizes Curriculares Nacionais, pois aborda brevemente a crise ambiental em que o mundo passa atualmente, as preocupações que devem ser tomadas em relação ao Meio Ambiente, e a busca por novos valores e atitudes de todos.

Em outro trecho, o documento aborda alguns pontos polêmicos relacionados ao debate ambiental, tentando desmistificar alguns pontos que podem trazer empecilhos na defesa do meio ambiente. Aqui os PCN são bem claros, afirmando que é um problema associar apenas a qualidade de vida com a riqueza material, pois é evidente que a ausência de água tratada ou um ar poluído vai prejudicar a vida de todos, sem exceção.

Outra parte do documento em questão refere-se em ensinar e aprender Educação Ambiental, contribuir para a formação de cidadãos conscientes, mostrando que isso é necessário estar presente no cotidiano escolar por meio de projetos, inserção do tema dentro das disciplinas, desenvolvendo uma postura crítica no aluno.

Os PCN também apontam a necessidade de se trabalhar a Educação Ambiental de modo transversal, e que cada professor deve abordar a questão ambiental adequando-se ao seu conteúdo dentro de sua área, a fim de deixar claro e objetivo os valores que devem ser transmitidos. Em sua última parte, os PCN apresentam os conteúdos e critérios adotados e como os temas devem 
ser tratados para atingir o objetivo desejado. Foi adotado como critério de seleção de temas a preocupação por questões amplas, já que o tema em sim é bem complexo e possui grande diversidade no Brasil. A partir dos critérios adotados, foram eleitos três grandes blocos de conteúdo: A Natureza "cíclica" da Natureza; Sociedade e Meio Ambiente; e Manejo e Conservação Ambiental. Esses blocos não são fechados, ou seja, devem ser apresentados de acordo com o ano em que está sendo ensinado e pode ser modificado pelo professor na medida em que ele achar necessário, estando livre a forma como esses assuntos devem ser abordados, respeitando-se a faixa etária e o caráter transversal de como o Meio Ambiente deve ser abordado.

\section{PCN em Ação - Meio Ambiente na Escola}

De modo complementar aos PCN, este é documento ainda mais específico sobre o assunto de meio ambiente. Apresenta pontos importantes de como trabalhar a Educação Ambiental dentro do contexto escolar, mostrando um favorecimento de construções de propostas pedagógicas interligadas com as mais diferentes áreas do conhecimento. (BRASIL, 2001). São seis os objetivos dos PCN em Ação, sendo que eles apresentam pontos importantes desde a formação continuada dos professores dentro dos ambientes escolares adentrando até as secretarias de educação. Dentre as ações abordadas nos objetivos vale destacar os encontros de estudos, debates e reflexões acerca dos temas.

A grande ideia dos PCN em Ação é mostrar ao professor que a temática ambiental já está introduzida no contexto escolar dentro das disciplinas existentes, evidenciando problemas ambientais, conflitos sociais, econômicos e históricos e as relações que tanto alunos como os próprios professores podem fazer com o meio em que vivem.

Há, por fim, uma parte destinada a formação de professores, pois para se aplicar projetos em sala de aulas é necessário professores bem preparados e capazes de colocar em prática o que os documentos apresentam de uma forma geral.

\section{Base Nacional Comum Curricular (BNCC)}

A Base Nacional Comum Curricular (BNCC) deverá nortear os currículos das escolas de todo o Brasil, desde as da rede pública de ensino até as da rede particular, contendo os conhecimentos essenciais, as competências e as aprendizagens pretendidas para todos os alunos da Educação Básica do Brasil, desde a Educação Infantil até o Ensino Médio (BRASIL, 2017b).

A BNCC vem para alinhar as políticas educacionais no âmbito federal, estadual e municipal em diversas vertentes, dentre elas a formação de professores, a formulação do conteúdo que deve ser ensinado, a avaliação e a infraestrutura adequada no ambiente escolar, para que os alunos possam desenvolver suas habilidades, para uma formação humana integral (BRASIL, 2017c). 
A BNCC está ancorada no Artigo 210 da Constituição, que prevê: "serão fixados conteúdos mínimos para o ensino fundamental, de maneira a assegurar formação básica comum e respeito aos valores culturais e artísticos, nacionais e regionais" (BRASIL, 1988). A Lei de Diretrizes e Bases da Educação (LDB) também prevê, no Artigo 90, inciso IV, que deve-se "estabelecer, em colaboração com os Estados, o Distrito Federal e os Municípios, competências e diretrizes para a educação infantil, o ensino fundamental e o ensino médio, que nortearão os currículos e seus conteúdos mínimos, de modo a assegurar formação básica comum" (BRASIL, 1996).

Por fim a Lei no 13.005/2014, que promulgou o Plano Nacional de Educação (PNE), reitera a necessidade de uma Base Nacional Comum com o objetivo de aprendizagem e desenvolvimento dos alunos (BRASIL, 2014).

Vale ressaltar que existem pontos importantes nos fundamentos pedagógicos da Base Nacional Comum Curricular, ou seja, um deles é a utilização de conteúdos curriculares com o propósito de adquirir conhecimento de modo a aplicá-lo no cotidiano do aluno, dando-se o nome de "competências", dentre elas: mobilização e aplicação dos conhecimentos escolares - conceitos, procedimentos, valores e atitudes (BRASIL, 2017c).

Além disso, existe um grande compromisso da BNCC com a educação integral, ou seja, que seu conhecimento deva ser global, capaz de formar pessoas autônomas, preocupadas com os desafios da sociedade. Para isso, a aprendizagem do aluno deve estar sintonizada com suas necessidades, possibilidades e interesses (BRASIL, 2017c). Dessa forma o aluno deve ser protagonista no seu ensino, aplicar seu conhecimento na vida real, solucionar problemas, e contextualizar o conteúdo escolar com seu dia-a-dia.

Assim a BNCC adota dez competências gerais, ligando conhecimento, habilidades, atitudes e valores dos alunos ao longo do período escolar. É possível observar que das competências que a BNCC aborda, existe uma especial preocupação com a cidadania, autonomia, saúde física e emocional e resolução de conflitos de diversas naturezas, buscando tornar o aluno uma pessoa mais justa, democrática e inclusiva (BRASIL, 2013).

A BNCC estará estruturada em 3 níveis, abordando sempre as principais competências de cada uma dessas etapas: Ensino Infantil, Ensino Fundamental e Ensino Médio.

Partindo para a Educação Infantil, que configura como o início da vida escolar dos alunos, deve ser assegurado seis direitos aos alunos: a) conviver; b) brincar; c) participar; d) explorar; e) expressar; e f) conhecer-se. $O$ aluno deve ser acompanhado de perto pelo professor, para que dessa forma possa ocorrer o acompanhamento, a intervenção em seu processo de ensino aprendizagem e em seu desenvolvimento.

O professor deve refletir sobre suas práticas pedagógicas para propiciar os campos de experiências para que o aluno possa aprender e efetuar seu desenvolvimento: a) O eu, o outros e os nós; b) Corpo, gestos e movimentos; 
c) Traços, sons, cores e formas; d) Oralidade e escrita; e e) Espaços, tempos, quantidades, relações e transformações. Esses campos de experiência permitem que os alunos sejam acompanhados através de suas experiências concretas, sendo possível realizar um acordo curricular para assim entrelaçar os seus conhecimentos.

A transição da Educação Infantil para o Ensino Fundamental deve ser realizada com muita calma, atenção e equilíbrio, pois é necessária uma adaptação do aluno neste processo, já que a continuidade dos estudos, desse percurso que o aluno irá realizar é de extrema importância em sua vida.

Com o prosseguimento dos estudos temos o Ensino Fundamental também na Educação Básica, sendo ele organizado em quatro áreas de conhecimento: a) linguagens (englobando Língua Portuguesa, Arte, Educação Física, Língua Inglesa), b) matemática, c) ciências da natureza, e d) ciências humanas (englobando História e Geografia).

Com isso, cada área de conhecimento terá suas competências especificas de área para os alunos durante os nove anos do Ensino Fundamental e também as componentes específicas de cada componente (Língua Portuguesa, Arte, Educação Física, Língua Inglesa, História e Geografia) fazendo com que tenha uma articulação horizontal entre as áreas e uma articulação vertical entre os anos iniciais e os anos Finais do Ensino Fundamental.

Outro ponto abordado na BNCC é em questão das habilidades relacionadas aos objetos de conhecimento, relacionando isso tudo com as diferentes componentes curriculares presentes no Ensino Fundamental. Essas habilidades são essenciais para os alunos e devem estar incluídas nas escolas em diferentes contextos.

A forma de apresentação adotada na BNCC tem por objetivo assegurar a clareza, a precisão e a explicitação do que se espera que todos os alunos aprendam na Educação Básica, fornecendo orientações para a elaboração de currículos em todo o País, adequados aos diferentes contextos (BRASIL, 2017d).

Neste ponto a BNCC, busca alinhar o Ensino, porém em forma de orientações, deixando tudo muito mais claro de como deve ser desde a Educação Infantil até o Ensino Médio, com cuidados nos períodos transitórios, que são essenciais para os alunos, consolidando o aprendizado dos anos anteriores e possibilitando um aprendizado novo, ampliando sua linguagem, experiência, compreensão desde a parte social, cultura, história, tecnologia e meio ambiente (BRASIL, 2017g).

Em relação aos anos finais do Ensino Fundamental, os alunos se deparam com um nível maior de complexidade de assuntos estudados, 
devendo assim consolidar a autonomia dos estudantes e utilizar ferramentas para auxiliar mais efetivamente os jovens, dentre eles o uso da tecnologia, que deve estar presente no ambiente escolar engajando-os e tornando-os protagonistas, porém devem-se tomar cuidados para que esta ferramenta não seja mal utilizada, transformando respostas e análises em algo superficial, pois se deve tornar o aluno crítico e reflexivo (BRASIL, 2017g).

Assim, nos Anos Finais do Ensino Fundamental deve-se estabelecer uma articulação com os estudantes e buscar uma relação com seus desejos em relação ao futuro preparando-os da melhor forma possível para o Ensino Médio.

O Novo Ensino Médio também tem como norteamento a Base Nacional Comum Curricular, definindo as competências para os alunos. São ao todo 1800 horas abrangendo as quatro áreas de conhecimento, sendo as mesmas do Ensino Fundamental, mas claro ocorrendo um aumento de disciplinas de acordo com a área de conhecimento, como exemplo as Ciências Humanas que irão compreender História, Geografia, Filosofia e Sociologia.

Terão como disciplinas obrigatórias durante os três anos a Língua Portuguesa e a Matemática. Por fim as outras horas que complementarão o Ensino Médio serão baseadas no aprofundamento acadêmico de áreas eletivas: a) linguagens e suas tecnologias; b) matemática e suas tecnologias; c) ciências da natureza e suas tecnologias; d) ciências humanas e sociais aplicadas; e e) formação técnica e profissional. As escolas ficarão responsáveis por organizar seus currículos de acordo com a demanda de alunos para cada área, sempre seguindo a BNCC.

\section{A Educação Ambiental nas Versões preliminares da BNCC}

A primeira versão da BNCC teve milhares de contribuições de especialistas, comunidade acadêmica, redes de Educação, organizações, e até mesmo contribuições individuais em sua primeira versão. Ela foi disponibilizada por seis meses (outubro/2015 a março/2016) para que o público pudesse colaborar (BRASIL, 2017d).

Nesta primeira versão da BNCC é já possível perceber-se que a Educação Ambiental não é citada em nenhuma parte das mais de 300 páginas de texto que contém o documento. Porém deve ser assinalado que a palavra "ambiental" é observada 32 vezes no texto, sendo a sua maioria relacionada à degradação ambiental, impactos que podem ser causados no meio ambiente ou até mesmo abordando a parte de gestão ambiental, como pode ser observado em um dos títulos presentes nesta versão: "Os Ecossistemas, Gestão Ambiental e Diversidade Sociocultural” (BRASIL, 2016a).

Neste tópico, especificamente, aborda a parte ambiental como: 
A problemática ambiental é um assunto recorrente e relevante, algumas questões serão discutidas nessa unidade, tais como: quais são os principais problemas ambientais locais, regionais e mundiais? Como podemos remediar situações de degradação? Como o conhecimento de diferentes povos pode auxiliar na manutenção e na preservação do ambiente? Para isso, é importante que seja tratado o conceito de ecossistema, bem como seu funcionamento e manejo, além de conceitos como sustentabilidade e serviços ambientais (BRASIL, 2016a).

A questão ambiental é perceptível em partes do documento relacionadas à Química, Biologia, contextualização histórica, entre outras, havendo desta forma uma iniciativa de colocar a questão ambiental dentro da BNCC de uma forma ampla, pensando em aumentar os pontos a serem explorados nas versões seguintes a aprimorar o documento.

Por se tratar de uma primeira versão é relativamente boa a abordagem de temas transversais, dentre eles meio ambiente, ética, direitos humanos, sexualidade, entre outros.

Após muitos debates em seminários que ocorreram entre 23 de junho e 10 de agosto de 2016, foi publicada a segunda versão da BNCC. As Secretarias Estaduais de Educação em todas as Unidades da Federação, com a coordenação do Conselho Nacional de Secretários de Educação (Consed) e da União Nacional dos Dirigentes Municipais de Educação (Undime), foram os órgãos competentes responsáveis pela realização desses debates, que contaram com a participação de mais de 9 mil professores, gestores, especialistas.

Vale ressaltar que a segunda versão da BNCC foi indagada/ponderada por especialistas do mundo inteiro e do Brasil, sendo estes pareceres encaminhados ao Comitê Gestor da Base Nacional Comum Curricular e Reforma do Ensino Médio (BRASIL, 2017e).

Esta versão sem dúvida é a mais completa em relação a temas transversais, e aborda outros tantos temas das mais diversas formas. Nela já aparecem mudanças profundas frente à primeira versão, dentre elas pode-se citar a presença da Educação Ambiental em 26 oportunidades.

O documento, com mais de 650 páginas, aborda sobre a Educação Ambiental no Brasil e no mundo, com embasamentos legais, tal qual a Lei 9.795/99, e faz referência à Conferência de Estocolmo, bem como aos avanços que a Educação Ambiental apresentou frente a outras tantas conferências e inclusive a RIO 92 e a RIO + 20 (BRASIL, 2016b).

A terceira versão da BNCC foi apresentada pelo Ministério da Educação (MEC) no dia 6 de abril de 2017, entregue pelo Ministro da Educação para o Conselho Nacional de Educação (CNE). Após a entrega desta terceira versão pode-se verificar que nela não há mais menções sobre Educação Ambiental, algo que estava previsto em algumas competências nos primeiros documentos

revista brasileira educação ambiental 
que foram produzidos e disponibilizados. Algo que aparece um pouco é em relação à sustentabilidade, mas muito pouco para a importância deste tema.

Com a terceira versão finalizada, ocorreram algumas audiências públicas no Brasil, sendo uma em cada região do país para que pudessem ouvir as pessoas para a homologação final da Base ocorrida em dezembro de 2017.

Mesmo com essas audiências pode-se observar que a Educação Ambiental foi pouco citada ou simplesmente nem mencionada em nenhum momento de algumas delas.

Foi possível observar um número razoável de colaborações recebidas pelo $\mathrm{CNE}$, sendo um total de 619. A grande maioria (337) foram críticas em pontos da BNCC, outras 233 foram de propostas e mais 49 mostrando aspectos positivos (SALDAÑA, 2017).

A Rede Paulista de Educação Ambiental (REPEA) encaminhou, por ocasião da audiência pública ocorrida em 25 de agosto de 2017 em São Paulo, um documento apontando algumas críticas à terceira versão da BNCC. Nesse documento, a REPEA questiona qual seria o motivo para a ausência dos Temas Transversais previstos nos PCN (mencionados brevemente na terceira versão da BNCC como "temas integradores"), lembrando que a continuidade de políticas públicas e seu aperfeiçoamento é ponto indispensável de um país que, mais do que propostas de governo, possui programas de Estado. Aponta também alguns erros pontuais de redação que chamaram a atenção. Terminam o documento marcando sua posição política, comunicando que os educadoras e educadores não iriam calar à imposição de uma Base Nacional Comum Curricular, pois sua luta pela defesa da Educação Pública contava com o apoio de entidades nacionais que não reconhecem a terceira versão da Base como se apresentava, afetando a Educação Infantil, a Educação Básica, excluindo o Ensino Médio do texto e ameaçando a autonomia dos sistemas de ensino, das escolas e dos educadores do país.

Ressalta-se, que após as três versões ainda existiam muitas críticas em relação ao documento, várias mudanças que deveriam ser realizadas, dentre elas a inclusão da Educação Ambiental na versão definitiva da BNCC.

\section{Versão Final da BNCC - Educação Infantil e Ensino Fundamental}

A versão final da Base Nacional Comum Curricular relacionada e Educação Infantil e Ensino Fundamental foi aprovada em 15 de dezembro de 2017 pelo Conselho Nacional de Educação (CNE) por 20 votos a 3, e homologada em Brasília pelo Ministro da Educação no dia 20 de dezembro de dezembro de 2017 com uma cerimônia contando com a presença do então presidente da República Michel Temer (BRASIL, 2018a).

Pode-se afirmar que houve algumas mudanças em relação à terceira versão. O documento foi tratado pelo governo como a "terceira versão da Base Nacional Comum Curricular revisado", mas em outras esferas é possível encontrar denominação de "quarta versão". Independente do nome, as 
mudanças em relação à terceira versão foram poucas, principalmente dentro da Educação Ambiental.

Foi acrescentado nesta nova versão um texto mais amplo sobre Ensino Religioso, tornando-o obrigatório no currículo escolar de todos os estudantes, este tema foi incluído como uma área de conhecimento seguindo os mesmos modelos das outras áreas, como a de Matemática, Linguagens, entre outras.

Vale ressaltar que outro ponto importante que foi alterado em relação à versão anterior foi sobre a alfabetização, onde as crianças devem ser alfabetizadas até os sete anos de idade, diferente do que ocorria até então, onde as crianças deveriam ser alfabetizadas até o terceiro ano do ensino fundamental, quando completam oito anos de idade.

Nota-se que em relação à Educação Ambiental é fato que se pode afirmar que não houve avanços, já que nesta versão final ela é citada apenas uma vez, em meio a outros temas transversais, como é mostrado abaixo (BRASIL, 2017a):

Por fim, cabe aos sistemas e redes de ensino, assim como às escolas, em suas respectivas esferas de autonomia e competência, incorporar aos currículos e às propostas pedagógicas a abordagem de temas contemporâneos que afetam a vida humana em escala local, regional e global, preferencialmente de forma transversal e integradora. Entre esses temas, destacam-se: direitos da criança e do adolescente (Lei $\mathrm{n}^{\circ}$ 8.069/1990), educação para o trânsito (Lei no 9.503/1997), Educação Ambiental (Lei no 9.795/1999, Parecer CNE/CP no 14/2012 e Resolução CNE/CP nำ2/2012), educação alimentar e nutricional (Lei ํㅜ 11.947/2009).

Faz-se necessário ressaltar que este trecho é o único em todo o documento de 470 páginas em que temos a Educação Ambiental citada, mostrando que para o governo este tema ficou completamente em segundo plano na montagem de uma Base que será utilizada por muitos anos em todo o território Nacional.

Pode-se afirmar que faltaram debates para embasar a aprovação da Base, já que ocorreram diversas audiências públicas e que foram enviadas muitas sugestões via internet por diversas pessoas e entidades. O governo afirmou que as audiências públicas e sugestões foram o suficiente, mas não informou como todo esse material enviado foi analisado e sistematizado, faltando assim transparência neste processo.

Segundo o Ministério da Educação, os temas tratados nas audiências são pertinentes e relevantes, nada, além disso, e do trabalho em cooperação com os relatores da BNCC foi dito para deixar claro como foram sistematizados os dados recebidos (SALDAÑA, 2017). 


\section{Versão Final da BNCC - Ensino Médio}

Um ano após a aprovação da BNCC relacionada à Educação Infantil e Ensino Fundamental foi aprovada a BNCC do Ensino Médio, em 14 de dezembro de 2018. O documento contém um pouco mais de 150 páginas e possui uma divisão por áreas de conhecimento, as mesmas previstas na reforma do ensino médio.

Vale a pena apontar, de uma forma bem enfática, que este documento não aborda os temas transversais de ensino da forma se esperaria devido a sua importância. A Educação Ambiental é citada apenas uma vez em todo o arquivo, colocando a responsabilidade aos sistemas de ensino e escolas abordarem de forma contextualizada, reproduzindo o mesmo trecho já presente na BNCC do Ensino Fundamental citado (BRASIL, 2017a; 2018b):

Essa falta de preocupação com os temas transversais mostra o quanto 0 Governo Federal está deixando de lado questões que deveriam ser incluídas como prioridade e deixa claro que a falta de preocupação com a qualidade da educação do país.

\section{Principais críticas referentes aos documentos que abordam a Educação Ambiental}

Analisando-se diversos autores, pode-se observar que a Educação Ambiental é fundamental para o país, sendo necessário ser implantado de uma forma eficaz e satisfatória.

Percebe-se que a Lei 9.795/99 é bem avaliada por vários especialistas, entendida como uma regulamentação prática que deixa mais claro como implementar a Educação Ambiental no Brasil (ADAMS, 2012). Em conformidade com a Lei 9.795/99, as Diretrizes Curriculares Nacionais para Educação Ambiental, também sendo muito bem avaliadas por diversos autores, dentre eles Santos e Costa (2015), Furtado (2009), Moura e Hirata (2013). Sendo assim, é possível afirmar que a Lei 9.795/99 e as Diretrizes são vistas com bons olhos tanto pelo governo quanto por diversos especialistas que entendem que essas Diretrizes foram essenciais para o embasamento da Lei, sendo assim são documentos sólidos e amplos.

O mesmo não pode ser dito em relação aos PCN. Neto e Kawasaki (2013), por exemplo, criticam principalmente o fato deles se apresentarem de uma forma muito isolada em um único arquivo, sendo que seria necessária sua apreciação de forma interdisciplinar.

Outra crítica bem relevante em relação aos PCNs, principalmente na parte dos temas transversais foi os trabalhos que envolviam estes temas. Eles não possuem orientações claras, já que existe uma busca pela centralidade do currículo nas disciplinas existentes (LOPES, 2005; GALIAN, 2014)

Assim, existem pesquisadores como Bernardes e Prietro (2010) que criticam a colocação do meio ambiente/Educação Ambiental de forma 
interdisciplinar, Esses autores sugerem a criação de uma disciplina chamada Educação Ambiental em todos os níveis educacionais para assim ser possível fazer com que o aluno tenha mais tempo, material e trabalho efetivo para ter uma formação mais crítica, já que de fato em muitas escolas a transversalidade no Ensino não funciona de fato (FOEPPEL; MOURA, 2014).

As críticas à esses documentos, no entanto, são muito menores do que as que a Base Nacional Comum Curricular vem recebendo, ora por ausência de temas importantes como a Educação Ambiental (temas transversais de um modo geral), ora por excesso de debate em apenas um tema especifico.

Segundo Sorrentino e Portugal (2016), é necessário que na Base Nacional Comum Curricular sejam inseridas as Diretrizes de Educação Ambiental de forma bem clara, para que assim o MEC, em conjunto com as Secretarias de Educação dos Estados, implante instrumentos de políticas públicas que envolvam a comunidade escolar como um todo. Afirma que um texto entregue à pedido do próprio MEC como subsídio para o debate de versões anteriores da BNCC, já enfatizava a importância da escola ser capaz de fortalecer nas crianças e jovens o compromisso com a vida e a construção de um mundo melhor para todas as pessoas e demais seres do Planeta. Para os autores, conhecer exige curiosidade, questionamento e criticidade para a compreensão das causas, de modo a propiciar a superação dos problemas e fomentar a construção de projetos coletivos que antecipem os futuros desejados. Partindo desse pressuposto, a ausência de explicitação dos temas transversais e de seu diálogo com todas as disciplinas e conteúdos curriculares, em especial a falta de uma Educação Ambiental que discuta as diversas dimensões da sustentabilidade historicamente debatidas e amadurecidas ao longo de quatro décadas, impede que a BNCC promova o alcance desses objetivos.

Outra crítica recorrente em relação à BNCC, segundo Santinelo et. al. (2016), é a ausência do termo Educação Ambiental no documento, já que este tema deve ser interdisciplinar e aparecer em todos os tópicos, porém não é isso que acontece, já que é citado apenas uma vez no documento.

Segundo Guimarães (2004), o papel da escola deve ir muito além de uma sensibilização de problemas ambientais, deve ser mais amplo, trabalhar de uma forma interdisciplinar e de uma maneira efetiva.

A criação da Base é uma tentativa de padronização do conteúdo a ser aplicado nas escolas de todo o Brasil, porém deve-se tomar cuidado com aspectos regionais de cada parte do Brasil e abordar temas importantes com uma maior clareza, algo que não é observado no documento final. 


\section{Conclusões}

A Educação Ambiental, fundamental para todos os cidadãos, se tornou importante no Brasil a partir da Constituição de $1988 \mathrm{com}$ a inclusão do artigo 225 relacionado ao Meio Ambiente, e se tornou obrigatória no Ensino Brasileiro a partir da aprovação da Lei 9.795/99. As Diretrizes Curriculares Nacionais para a Educação Ambiental e os Parâmetros Curriculares Nacionais vieram para regulamentar essa obrigatoriedade.

No entanto, o governo federal aprovou em dezembro de 2017 a nova Base Nacional Comum Curricular, que deve substituir os PCN e nortear os currículos escolares, com a quase total ausência da Educação Ambiental. Ficou evidenciado um retrocesso ante toda a regulamentação anterior, mesmo após diversos debates sobre os documentos preliminares da BNCC, nos quais especialistas citaram a ausência de temas transversais. $O$ governo ignorou 0 assunto e publicou um documento com esta grande ausência. A Educação Ambiental, mesmo quando estava presente em documentos curriculares anteriores já era ignorada por algumas instituições de ensino. Ausente na nova Base, esperara-se que, infelizmente, deixe definitivamente de ser abordada em muitas escolas, apesar da importância contemporânea do tema e do Brasil possuir uma legislação bem consistente que obriga a sua presença em todos os níveis escolares.

Segundo Dias (2018) a Base Nacional Comum Curricular (BNCC) trará alterações singulares em todos os currículos e, neste cenário, discutir a pluralidade de opiniões e aspectos relevantes deverá ser responsabilidade tanto dos gestores públicos da educação no Brasil, quanto de toda a sociedade comprometida com as mudanças necessárias que beneficiem a todos.

\section{Referências}

ADAMS, B. G. A Importância da Lei 9.795/99 e das Diretrizes Curriculares Nacionais da Educação Ambiental para docentes. Monografias Ambientais REMOA/UFSM, Santa Maria, v. 10, n. 10, p. 2148 - 2157, 2012.

BARBOSA, L.C. Políticas Públicas de Educação Ambiental numa sociedade de risco: Tendências e desafios no Brasil. Brasília, 2008. 21p.

BERNARDES, M. B. J. e PRIETO, É. C. Educação Ambiental: disciplina versus tema transversal. Revista Eletrônica do Mestrado em Educação Ambiental. Rio Grande: FURG- RS, v.24, p. 176-178. 2010.

BRASIL, Ministério da Educação. Programa Parâmetros em Ação Meio Ambiente na Escola. Brasília: MEC. 2001.

BRASIL, Ministério da Educação. Base Nacional Comum Curricular - 1o Versão. Brasília: MEC. 2016a.

BRASIL, Ministério da Educação. Base Nacional Comum Curricular - 2음 Versão. Brasília: MEC. 2016b. 
BRASIL, Ministério da Educação. Base Nacional Comum Curricular Perguntas Frequentes. Brasília: MEC. 2017 a.

BRASIL, Ministério da Educação. A Base Nacional Comum Curricular Introdução. Brasília: MEC. 2017 b.

BRASIL, Ministério da Educação. A Base Nacional Comum Curricular Apresentação. Brasília: MEC. 2017 c.

BRASIL, Ministério da Educação. Os relatórios analíticos e pareceres relativos à segunda versão podem ser consultados no site. Base Nacional Comum Curricular. Brasília: MEC, 2017 d.

BRASIL, Ministério da Educação. A Base Nacional Comum Curricular - A Estrutura da BNCC. Brasília: MEC. 2017 e.

BRASIL, Ministério da Educação. Novo Ensino Médio - Dúvidas. Brasília: MEC. $2017 f$.

BRASIL, Ministério da Educação. A Base Nacional Comum Curricular - A Etapa do Ensino Fundamental. Brasília: MEC. $2017 \mathrm{~g}$.

BRASIL, Ministério da Educação. Base Nacional Comum Curricular - Ensino Médio. Brasília: MEC. 2018 a.

BRASIL, Ministério da Educação. Etapa do Ensino Médio é homologada e Base Nacional Comum Curricular está completa. Brasília: MEC. 2018b.

BRASIL, Secretaria de Direitos Humanos da Presidência da República. Caderno de Educação em Direitos Humanos. Educação em Direitos Humanos: Diretrizes Nacionais. Brasília: Coordenação Geral de Educação em SDH/PR, Direitos Humanos, Secretaria Nacional de Promoção e Defesa dos Direitos Humanos, 2013.

BRASIL. Lei no 13.005, de 25 de junho de 2014. Aprova o Plano Nacional de Educação - PNE e dá outras providências. Diário Oficial da União, Brasília, 26 de junho de 2014.

BRASIL. Lei número 9.795 de 27 de abril de 1999. Política Nacional de Educação Ambiental, Diário Oficial da União, Brasília, 1999.

CZAPSKI, S. A Implantação da Educação Ambiental no Brasil. Brasília: Coordenação de Educação Ambiental do Ministério da Educação e do Desporto, 1998. 166p.

DIAS, E.S.A.C. Formar e pesquisar para quê? Ensaio: aval.pol.públ.Educ. vol.26 no.98 Rio de Janeiro jan./mar. 2018

DIAS, G. F. Educação Ambiental: princípios e práticas. 9.ed. São Paulo: Gaia, 2004.

FOEPPEL, A. G. S.; MOURA, F. M. T. Educação Ambiental como Disciplina Curricular: Possibilidades Formativas. Revista da SBEnBIO, n. 7, 2014. 
FURTADO, D. J. Os caminhos da educação ambiental nos espaços formais de ensino-aprendizagem: qual o papel da política nacional de Educação Ambiental? Rev. eletrônica Mestr. Educ. Ambient. Rio Grande, v. 22, janeiro a julho de 2009.

GALIAN, C. V. A. Os PCN e a Elaboração de Propostas Curriculares no Brasil. Cadernos de Pesquisa, v. 44, n. 153, p. 648-669, 2014.

GUIMARÃES, M. A Formação de Educadores Ambientais. Campinas: Papirus, 2004.

LOPES, A. R. C. Política de currículo: recontextualização e hibridismo. Currículo sem Fronteiras, v. 5, n. 2, p. 50-64, 2005.

LÜDKE, M.; ANDRÉ, M. E. D. A. Pesquisa em Educação: Abordagens Qualitativas. São Paulo: EPU, 1986. 39 p.

MOURA, J. D. P.; HIRATA, C. A. A Educação Ambiental em Debate. Pró Docência Revista Eletrônica das Licenciaturas/UEL, v. 1, n. 5, 2013.

NETO, D. V.; KAWASAKI, C. S. "Meio Ambiente" é um tema transversal nos documentos curriculares nacionais do ensino fundamental? Camine: caminhos da educação, Franca, v. 5, n.1, 2013.

NOVICKI, V.; SOUZA, D.B. Políticas públicas de educação ambiental e a atuação dos conselhos de meio ambiente no Brasil: perspectivas e desafios. Ensaio: aval.pol.públ.Educ. vol.18 no.69 Rio de Janeiro Oct./Dec. 2010.

OLIVEIRA, L. Princípios da Radiação e Principais Acidentes Ocorridos no Mundo. 2016. 55f. Trabalho de Conclusão de Curso. Universidade Federal de São Paulo, Diadema, 2016.

PINHEIRO, L. R. D. Estudo sobre o Comportamento do Consumidor frente à Questão Ambiental. 2009. 150f. Dissertação de Mestrado. Universidade Municipal de São Caetano do Sul, São Caetano, 2009.

SALDAÑA, P. Gestão Temer acelera votação da Base Curricular sem novo debate. São Paulo, 2017. Disponível em: <http://www1.folha.uol.com.br/educacao/2017/12/1940027-gestao-temeracelera-votacao-da-base-curricular-sem-novo-debate.shtml>. Acesso em 02 dez. 2017.

SANTINELO, P. C. C.; ROYER, M. R.; ZANATTA, S. C. A Educação Ambiental no Contexto Preliminar da Base Nacional Comum Curricular. Pedafog. Foco, Iturama (MG), v. 11, n. 6, p. 104-115, 2016.

SANTOS, T. C.; COSTA, M. A. F. Um olhar sobre a Educação Ambiental expressa nas Diretrizes Nacionais para a Educação Ambiental. Revista Práxis. Ano VII, n. 13, p. 143-151, 2015.

SORRENTINO, M.; PORTUGAL, S. Educação Ambiental e a Base Nacional Comum Curricular. Relatório interno, MEC, 2016. 